\title{
Sensing the Social Field through Action Research: What's Important, What's Valid
}

\section{A Commentary on Pomeroy et al., "Exploring Action Research from a Social Field Perspective"}

Patricia A. Wilson

University of Texas

\section{Birthing a Global Field}

What I love about action research is its whole-person, in-the-moment, emergent nature. As action researchers, we are in service of the emergence of a greater whole, a gradual transformation process that births something new. As action researchers we know in our hearts when we have made a difference. But we do not claim agency. We serve as midwife to the social field's own emergence, helping it to know itself. It is this sense of wonder at midwifing the birth of something new that stands out to me in the article by the Presencing Institute's action research team (hereafter called 'the Team') as they describe their work with the remarkable process called GAIA.

In March of 2020, as the pandemic spread across the globe bringing lockdowns and social isolation, the Presencing Institute quickly designed and launched a 14-week global community-building event called GAIA—Global 
Activation of Intention and Action. Designed as a self-organizing platform, the event brought together thousands of change agents from around the globe. Through simultaneous Zoom rooms across multiple continents and multiple languages, the GAIA participants created over those 14 weeks a resonant social field-one that not only offered social connection but also deepened their awareness, individually and collectively, of what was calling them forward, what was theirs to do in this time of global crisis.

The Pomeroy et al. article describes the experience of the Presencing Institute's action research team as it engaged with the GAIA process. Team members embedded themselves in the process as co-participants to get a firstperson felt-sense of the experience. The Team also monitored the pulse of the social field with periodic surveys and focus groups in order to mirror back to the GAIA community its own process of evolution through the 14-week process.

\section{Sensing the Social Field}

I consider the article's primary contribution to the action research literature to be the Team's evocative description of a particular moment in their action research with the GAIA process. It is the moment when the Team moves from sense-making about the social field of the GAIA process to collectively sensing with the living, evolving social field the GAIA participants were enacting. This movement from sense-making to sensing deepens the way of knowing, from observing a system to becoming the system in a collective process of transformation. The social field opened up to the Team as they moved from sense-making to a relational awareness of a living system in an emergent process.

What sparked this transformative moment for the Team? The breakthrough moment came when the team members turned from analyzing survey results to journaling their inner experience, accessing their feelings and intuition about the GAIA process they were monitoring. Then they shared their feelings and intuition with each other to surface their collective knowing - a kind of embodied knowing that arises from a deep source. They envisioned the social field as a whole, as a living and evolving being. They began to sense the GAIA field opening up to them. A new relational awareness from within the living system emerged - the 'I', the 'we', the 'they' becoming one. From this place, the team members could access their deepest collective wisdom-their embodied, intuitive awareness of the social field as a living being. The deep dive of collective sensing opened their hearts. And they turned to nurture the living field's own evolution.

This is action research at its finest, articulated by the Team with evocative descriptions of the movement from sense-making about the social field to sensing the social field from within it. Underneath their words, you can feel the breakthrough and buoyance that the Team experienced, embodying the subtlety and depth of what Otto Scharmer calls the Field 3 experience (2015). This is what 'sensing the social field' means—how different from merely observing it! 
Our call as action researchers in academia is to make this way of knowing and doing visible, recognized, and appreciated for the depth and integrity it offers.

\section{The Morning After: A Post-Positivist Dilemma}

The post-partum blues in action research typically occur when you return to your academic home and try to tell your colleagues what you accomplished! Or try to write that article for a leading journal in your field. The question becomes this: how to convey the significance and validity of your work. Pomeroy et al. ask that very question.

I have faced that dilemma numerous times. I do action research with placebased communities-especially at-risk or vulnerable communities in the Global South (Wilson 2019). For action researchers, how we know if we were successful—or what worked and didn't—is easy: We feel it! We know by how the social field - the community that we have entered and become a part of responds to us and how it feels about itself and its own sense of agency. What didn't work along the way is not a failure, but a learning opportunity. (See the practice stories in Wilson, 2019, especially Chapters 2 and 7).

To convey the significance of my action research, I draw upon inspiring postpositivist methodologies. Awareness of post-positivist methodologies has blossomed over the last four decades, bringing ontological and epistemological depth to action research. These methodologies embrace relational, experiential, and embodied ways of knowing: subjective and intersubjective, intuitive and heart-based. They privilege wholes rather than parts and explore consciousness, both individual and collective. These ways of knowing do not dismiss the role of empirical data. Rather, they open a world of insight that is sometimes referred to as feminine ways of knowing, being, and doing. Action research is a means for holistically comprehending the subjective and intersubjective nature of a group process.

Relational action research, much of which comes out of the Social Innovation literature, is one of those ontological contributions (see Bartels 2020, Greenwood \& Levin 2007 and Frantzeskaki \& Rok 2018). The 'radical interdependence' work of Arturo Escobar (2017) on transition design, particularly noteworthy for its ontological roots in the ground-breaking insights of Maturana and Varela, is another. Otto Scharmer's work (2007), which also draws inspiration from Maturana and Varela, has provided many of us with a phenomenological framing that acknowledges a spiritual dimension of awareness in our practice (see Chapters 8 and 10 in Wilson 2019).

\section{Assessing Validity in Post-Positivist Research}

It is clear that the Team knew in their hearts how effective and impactful their action research with GAIA had been. But the right validity indicators can be useful for assessing results more finely and communicating them to others. Herr and Anderson (2005) offer four validity criteria which I consider to be supportive 
of the post-positivist relational methodology of action research. I offer my own definition of a fifth criterion.

1. Democratic validity refers to the extent to which action research is done in collaboration with all parties who have a stake in the problem or process under investigation.

The key indicator I use for democratic validity in action research is one question: Who owns the results? Certainly, the participants in the GAIA process owned the transformative results of their shared experiences over the 14 weeks. Such individual and collective 'ownership' was the Presencing Institute's intention and the outcome. If we look at the assessment process and feedback loops the action research team created, it is clear that the entire Team felt ownership of that process and its results.

The GAIA participants themselves, however, did not take ownership of the assessment process. They provided feedback to the action research team. To fully meet the criterion of democratic validity, the participants would need to co-create and co-conduct the assessment of their process with the action researchers. The results of the assessment would be 'owned' by all, not by the research team. As Bartels states (p. 2878), action research is "a relational process in which action researchers and stakeholders [participants] collaboratively craft interpretations, adapt research methods and stimulate change". While this distinction may not be relevant in the GAIA case, it is highly relevant to much academic-led action research in which place-based community action research runs the risk of becoming extractive rather than collaborative.

2. Outcome validity refers to an iterative process, a spiral, in which participants reframe the problem in an increasingly nuanced way, evidencing growing awareness of its deeper complexity.

The Team fully enacted that process among themselves, which they describe as culminating in the awareness of the social field's maturation process and a heart-opening toward what was theirs to do.

3.Catalytic validity is the degree to which the action research process changes the participants' views of themselves, their sense of purpose, of what is possible, and of what they can accomplish.

The Team witnessed a growing sense of purpose and intention among the GAIA participants in their two on-going focus groups. The Team's own sensing process was transformative as well: The team members view of themselves as a team, in their ways of knowing, and in their sense of purpose evolved as they realized they were there to hold and foster the social field's maturation.

4. Process validity assesses not only whether the process used produced desirable results, but also whether it created ongoing learning and action by the participants.

Meeting this criterion would require the research team to follow up periodically with the participants. It is the hope that many of the GAIA hubs will stay together as coaching circles and support groups to encourage each other 
forward in their intentions to create the landing pads for awareness-based systemic change across the globe.

5. Dialogic validity is defined by Herr and Anderson as feedback from other researchers who examine your action research process and results for alternative interpretations. I prefer to define dialogic validity as the quality of mutual understanding developed among and between action researchers and participants through deep listening. Through such dialogue we begin to notice and suspend (or adapt, says Bartels, 2878)) our pre-held assumptions, beliefs and knowledge. Deep dialogue becomes empathic and generative (Scharmer, 2007). It opens the door to participatory consciousness (Wilson, 231-2).

As the GAIA participants moved from seeing to sensing their own social field, their conversations grew deeper as well-more empathic, relational, and generative. The action research team experienced the same shift as they put aside the survey results and sank deeper into their embodied and intuitive knowing. The Team described their own dialogue as 'Bohmian', which involves changing the way the thought process itself occurs, individually and collectively, becoming aware of and suspending one's own assumptions, and creating shared meaning (Bohm, 2013).

\section{Summing Up}

Action research is "co-generative learning" with "ongoing and purposive redesign" (Greenwood and Levin, 2007, p. 133-4). It is a "deliberate yet emergent strategy for developing joint readings of unfolding events and crystalizing where to intervene and how to give shape to change" (Bartels, 2020, p. 2876). The gateway to transformational action research is co-sensing the social field through "total immersion in the particulars of the field-in the living presence of the phenomenon,... becoming one with the phenomenon you study" (Scharmer 2007, p. 147).

The Presencing Institute action research team's story of co-sensing and nurturing the social field of the GAIA process is a vibrant example of what action researchers are called to do: to be in service to the emergence of a greater whole, a transformation process that births something new.

\section{References and Suggested Sources}

Bartels, K. (2020). Transforming the relational dynamics of urban governance: How social innovation research can create a trajectory for learning and change. Urban Studies, 57(14), 2868-2884

Bohm, D. (2013). On dialogue. Routledge.

Burns, D. (2007). Systemic action research. Policy Press

Escobar, A. (2017). Designs for the pluriverse. Duke University Press. 
124 Sensing the Social Field Through Action Research: What's Important, What's Valid

Ewenstein, B. \& Whyte, J. (2007). Beyond words: Aesthetic knowledge and knowing in organizations. Organization Studies, 28(5), 689-708.

https://doi.org/10.1177/0170840607078080

Frantzeskaki, N. \& Rok, A (2018). Co-producing urban sustainability transitions knowledge with community, policy and science. Environmental Innovation and Societal Transitions, 29, 47-51. https://doi.org/10.1016/j.eist.2018.08.001

Greenwood D. \& Levin, M. (2007). Introduction to action research: Social research for social change. (2nd ed.). Sage.

Herr, K. \& Anderson, G. L. (2005). The Action Research Dissertation. Sage Publications.

Scharmer, O. (2007). Theory U. Society for Organizational Learning.

Scharmer, O. (2015, June 6). The blind spot: Uncovering the grammar of the social field. HUFFPOST. https://www.huffpost.com/entry/uncovering-the-grammar-of-the-socialfield_b_7524910

Wilson, P. A. (2019). The heart of community engagement: Practitioner stories from across the globe. Routledge. 